Article

\title{
Combining TerraSAR-X and Landsat Images for Emergency Response in Urban Environments
}

\author{
Shiran Havivi ${ }^{1}$ *, Ilan Schvartzman ${ }^{2}$, Shimrit Maman ${ }^{3}$, Stanley R. Rotman ${ }^{2}$ and \\ Dan G. Blumberg ${ }^{1}$ \\ 1 Earth and Planetary Image Facility, Department of Geography and Environmental Development, \\ Ben-Gurion University of the Negev, P.O. Box 653, Beer-Sheva 84105, Israel; blumberg@bgu.ac.il \\ 2 Department of Electrical and Computer Engineering, Ben-Gurion University of the Negev, P.O. Box 653, \\ Beer-Sheva 84105, Israel; ilan.schvartzman@gmail.com (I.S.); srotman@bgu.ac.il (S.R.R.) \\ 3 Homeland Security Research Institute, Ben-Gurion University of the Negev, P.O. Box 653, \\ Beer-Sheva 84105, Israel; tiroshs@gmail.com \\ * Correspondence: havivi@post.bgu.ac.il; Tel.: +972-52-358-9213
}

Received: 29 March 2018; Accepted: 17 May 2018; Published: 21 May 2018

Abstract: Rapid damage mapping following a disaster event, especially in an urban environment, is critical to ensure that the emergency response in the affected area is rapid and efficient. This work presents a new method for mapping damage assessment in urban environments. Based on combining SAR and optical data, the method is applicable as support during initial emergency planning and rescue operations. The study focuses on the urban areas affected by the Tohoku earthquake and subsequent tsunami event in Japan that occurred on 11 March 2011. High-resolution TerraSAR-X (TSX) images of before and after the event, and a Landsat 5 image before the event were acquired. The affected areas were analyzed with the SAR data using only one interferometric SAR (InSAR) coherence map. To increase the damage mapping accuracy, the normalized difference vegetation index (NDVI) was applied. The generated map, with a grid size of $50 \mathrm{~m}$, provides a quantitative assessment of the nature and distribution of the damage. The damage mapping shows detailed information about the affected area, with high overall accuracy (89\%), and high Kappa coefficient $(82 \%)$ and, as expected, it shows total destruction along the coastline compared to the inland region.

Keywords: InSAR coherence; NDVI; damage assessment; density map; tsunami; earthquake; GIS

\section{Introduction}

Natural and man-made disasters often cause severe economic and physical damage, the effects of which are potentially far more devastating in urban areas [1]. In the wake of a disaster, the effectiveness of the emergency response depends critically on the extent to which the damage assessment is both rapid and precise. To that end, remote sensing imagery, which can be used to assess the change over time of a given geographical area, and can rapidly map the damage with high accuracy and spatial coverage and at low cost [2]. Both optical and radar remote sensing data are increasingly being used for damage assessment [1,3-5].

The conventional technologies used in passive optical satellites operate mostly in the visible and infrared spectrum and are mainly used to map damage by visual interpretation [6-8] and to assess the vegetation status via the normalized difference vegetation index (NDVI). Conversely, synthetic aperture radar (SAR) is an active microwave sensor with day/night and all-weather operational capabilities that is highly sensitive to surface roughness, geometrical structures (e.g., built-up areas) and canopy volume in vegetated areas [9].

Changes in urban environments over time can be detected by using multi-temporal SAR intensity images. More detailed information can be obtained via interferometric SAR (InSAR) data, which are 
based on the differences in the phase information of the returning signals of two temporal images [10]. To detect and assess the damage caused by natural disasters, most published studies use either InSAR coherence [11-15] or the SAR intensity correlation [3,16,17], or both [18-20]. The accurate mapping that is essential to the planning and execution of an emergency response to a natural disaster can be obtained by using very high resolution (VHR) SAR data, such as that generated by the TerraSAR-X satellite. Its extremely high spatial resolution enables TerraSAR-X to discriminate between buildings and other elements more precisely than is possible using lower resolution technology $[5,21]$.

Assessments of the level of similarity between two SAR images can be provided by InSAR coherence change detection by using image amplitude and phase data. Coherence change detection is capable of detecting very subtle scene changes, expressed as loss of coherence, which may remain undetected using intensity data alone [22]. Loss of coherence measurements rely on the typically high coherence values exhibited by urban environments over time. Thus the scene changes (i.e., damage to the urban environment) caused by a natural disaster reflect loss of coherence that can be interpreted quantitatively in terms of the severity and extent of the damage [2]. To date, coherence results have mostly been analyzed by using the normalized difference (ND) of the coherence change $[14,18,19,23]$. For such an analysis, three SAR images are required (two from before and one from after the event) to generate pre- and co-event coherence maps. Among the principal drawbacks of this approach are its long processing and analysis times and its high costs. Furthermore, the accuracy of the results of the analysis can be low due to temporal decorrelation, which can occur when the dates of the SAR images are separated by long time intervals. Lastly, two pre-event images are not always available for change detection analyses.

In this study, we propose a new mapping approach for damage assessment based on the combination of SAR and multispectral data. The novelty of the proposed technique is set firstly in its ability to be implemented rapidly and accurately for urban damage assessment by a relatively small number of both optical and radar images. Secondly, the use of spatial analysis to produce a damage assessment map based on the coherence and NDVI imagery results was not yet tested. We demonstrate the effectiveness of this combined approach by applying it to the Tohoku earthquake and the subsequent tsunami event that occurred in Japan in 2011.

\section{Research Area}

On 11 March 2011, the magnitude 9 Tohoku earthquake occurred. With its epicenter located off Japan's eastern coast $\left(38.322^{\circ} \mathrm{N} / 142.369^{\circ} \mathrm{E}\right.$; Figure 1$)$, the earthquake also triggered a destructive tsunami with a wave height that exceeded $10 \mathrm{~m}$. Penetrating as far as $5 \mathrm{~km}$ inland when it struck the Japanese coast [24], the tsunami wave caused loss of human life and destruction of infrastructure. The extensive damage, assessed and reported by [25], included nearly 360,000 totally or partially destroyed houses. Although the seismic motion along the coast and inland accounted for some of the damage to housing, the tsunami was much more destructive, as it washed away many of the houses along the coast, and, in some places, it completely wiped out entire areas [25]. 


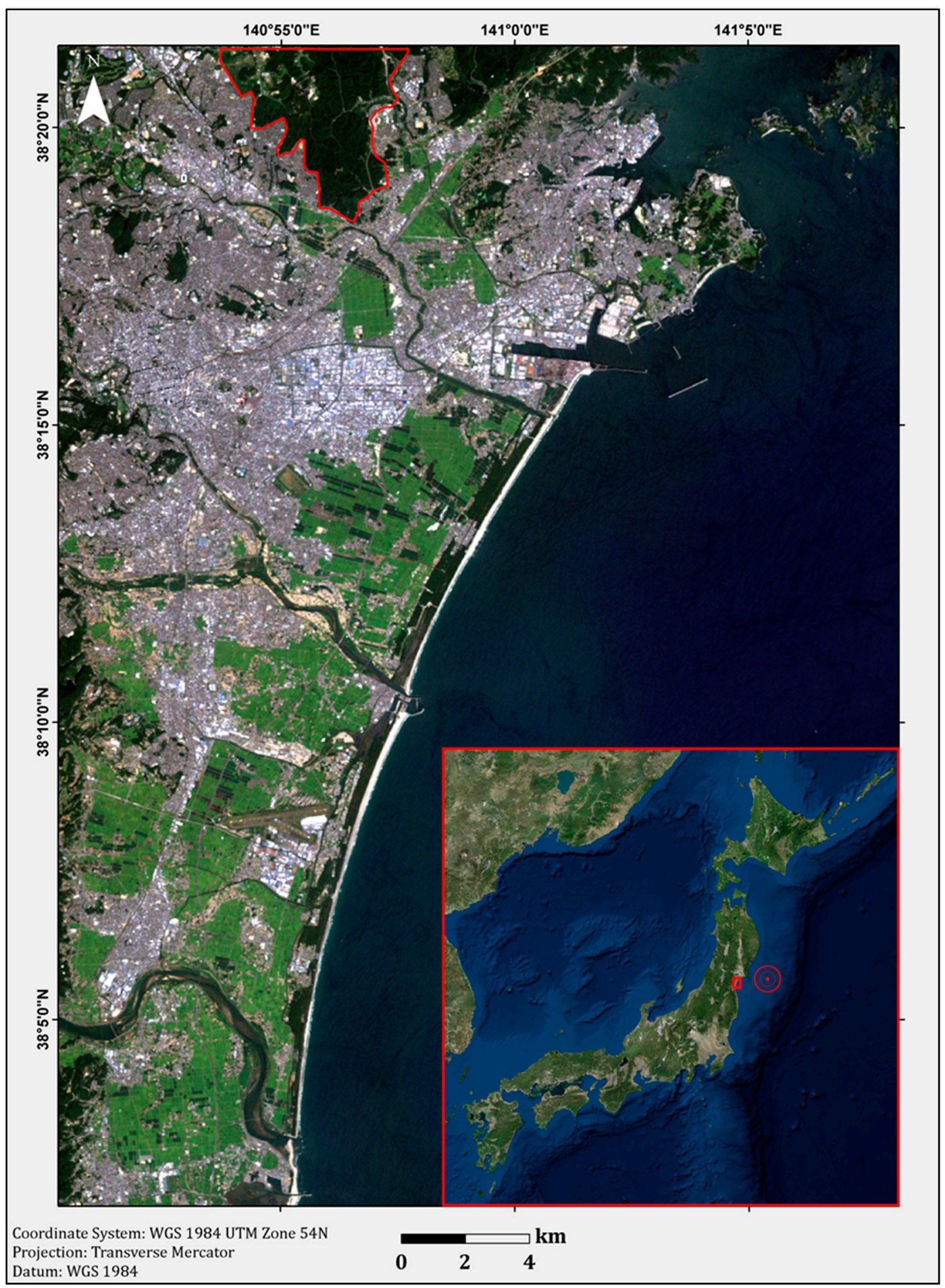

Figure 1. Pre-event Landsat 5 image (in visible bands 1 -blue, 2-green, and 3-red) of the research area from 24 August 2010. Inset: overview of the area most affected by the Tohoku earthquake and the earthquake's epicenter located at $38.322^{\circ} \mathrm{N} / 142.369^{\circ} \mathrm{E}$.

\section{Materials and Methods}

The methodology followed to create a damage assessment map is illustrated in Figure 2. 


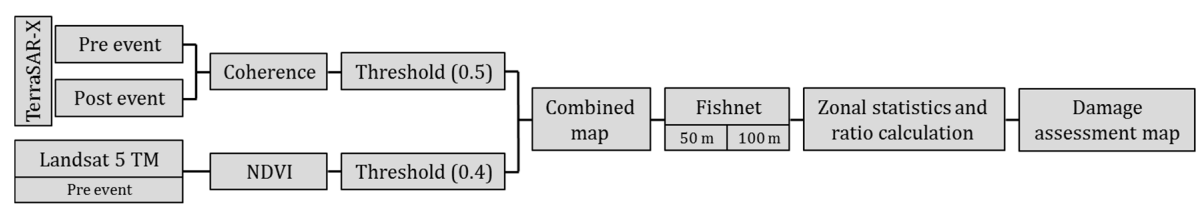

Figure 2. Research outline.

\subsection{Remote Sensing Data and Pre-Processing}

Two types of images, SAR and optical, were used to map the area affected by the earthquake and tsunami. SAR images comprised three high-resolution X-band $(3.1 \mathrm{~cm})$ pre- and post-event TerraSAR-X (TSX) images that were single-look complex (SLC) in a descending orbit direction. Data were acquired in StripMap mode with single $\mathrm{HH}$ polarization, an incidence angle of $37^{\circ}$, and pixel spacing of $2 \mathrm{~m}$ on the vertical axis and $0.9 \mathrm{~m}$ on the horizontal axis. Vegetation cover was mapped with a multispectral image taken by Landsat5 Thematic Mapper (TM) before the event. With moderate spatial resolution of $30 \mathrm{~m}$ /pixel (apart from band 6, with spatial resolution of $120 \mathrm{~m} /$ pixel), this multispectral image comprises seven spectral bands in the following ranges: VIS (bands 1-3), NIR (bands 4-5), TIR (band 6), and MIR (band 7), as specified in Table 1.

Table 1. Satellite images used in this study.

\begin{tabular}{|c|c|c|c|c|c|}
\hline \multirow{2}{*}{$\begin{array}{c}\text { Satellite } \\
\text { TerraSAR-X }\end{array}$} & \multirow{2}{*}{$\begin{array}{c}\text { Sensor Type } \\
\text { SAR }\end{array}$} & \multicolumn{2}{|c|}{ Acquisition Date } & \multirow{4}{*}{$\frac{\text { Resolution }}{2 \mathrm{~m}}$} & \multirow{4}{*}{$\begin{array}{c}\text { Spectral Properties } \\
\text { SLC } \\
\text { X-band } \\
\text { HH polarization }\end{array}$} \\
\hline & & Pre-event & 21 September 2008 & & \\
\hline & & Pre-event & 20 October 2010 & & \\
\hline & & Post-event & 12 March 2011 & & \\
\hline Landsat5 TM & Multispectral & Pre-event & 24 August 2010 & $30 \mathrm{~m}$ & 7 bands \\
\hline
\end{tabular}

The SAR images were co-registered, according to the 20 October 2010 image, which was selected as the reference image ('master') for both periods (before and after the event). The error RMS was up to 0.1 pixel, and an eight-point truncated sinc kernel was used for the interpolation [26,27]. Lastly, the Landsat5 image was georeferenced and resampled (to the TSX spatial resolution) according to the reference image.

\subsection{InSAR Coherence}

Based on both amplitude and phase, coherence change detection determines the stability of an area and shows where changes have occurred, depicting even subtle changes with levels of accuracy ranging from several millimeters to centimeters [9]. It, thus, quantifies the resemblance of a subset of the image between two points in time. The local coherence $\gamma$ (for each pixel) was calculated according to the formula:

$$
\gamma=\frac{\left|\sum_{\mathrm{k}=1}^{\mathrm{N}} \mathrm{f}_{\mathrm{k}} \mathrm{g}_{\mathrm{k}}^{*}\right|}{\sqrt{\sum_{\mathrm{k}=1}^{\mathrm{N}}\left|\mathrm{f}_{\mathrm{k}}\right|^{2} \sum_{\mathrm{k}=1}^{\mathrm{N}}\left|\mathrm{g}_{\mathrm{k}}\right|^{2}}}, \quad 0 \leq \gamma \leq 1
$$

where $f_{k}$ and $g_{k}$ are the complex SAR images, and $f_{k} g^{*}{ }_{k}$ is the expectation value operator. $N$ represents the size of the estimation window. Due to the high resolution of the TSX images, a reliable accuracy of the coherence could be achieved by calculating with a relatively small window size of $3 \times 5$ pixels in the azimuth and range directions, respectively. This window size contains enough pixels to ensure a minimum loss of information by providing a high spatial resolution and high contrast coherence image.

The coherence index $\gamma$ is an absolute value that represents a measure of the similarity between the two SAR images. The value of $\gamma$ ranges between 0 and 1 , wherein pixels with a good correlation are represented by high values, and pixels with no match are represented by low values $[9,22]$. Natural disaster-driven surface changes, such as damage to buildings and the presence of vegetation, lead to a loss of coherence. 


\subsection{Normalized Difference Vegetation Index (NDVI)}

To overcome the loss of coherence caused by changes in vegetation cover, a vegetation mask was applied by using the NDVI to identify (and remove) vegetated areas from the coherence map. One of the main advantages of the NDVI is its ability to distinguish vegetated from non-vegetated areas in the image. To do so, it exploits the contrast between the absorption of the red light (Band 3, $0.63-0.69 \mu \mathrm{m}$ ) by chlorophyll and the strong reflection of near-infrared radiation (Band 4, 0.76-0.90 $\mu \mathrm{m}$ ), which ensures that the difference between the red and infrared reflectance values is prominent and, therefore, that it yields a high ratio. The NDVI is defined as:

$$
\mathrm{NDVI}=\frac{\mathrm{NIR}-\text { red }}{\mathrm{NIR}+\text { red }}
$$

and generates values ranging from -1 to 1 (healthier/denser vegetation has higher values).

\subsection{Combining SAR and Multi-Spectral Data}

\subsubsection{Setting Thresholds}

To better focus on the man-made structures that were damaged by the earthquake and tsunami, a threshold was determined for the co-event coherence map (Figure 3) and the NDVI (Figure 4). A threshold value of $\geq 0.4$ was chosen for the NDVI, and, therefore, only the non-vegetated areas remained. Lower NDVI thresholds overestimated the vegetated area by displaying some of the built areas as vegetation. A threshold value of 0.5 for the co-event coherence map was determined according to [27], which showed it to be the lowest coherence value in an urban area for the same time interval (144 days) depicted between two images. By dividing the results into two classes, a binary map was generated in which $\leq 0.5$ was used for pixels that experienced change and $>0.5$ was used for those that experienced slight or no change. The coherence binary map was then overlain and masked by the threshold NDVI layer, after which both sets of results (thresholds of 0.4 and 0.5 ) were combined into one damage assessment map (Figure 5).

\subsubsection{Damage Assessment Map}

The generated map was classified into three classes: damaged, undamaged, and vegetated (Figures 5 and 6). This map, however, provides only a general view of the affected area. To obtain more detailed information about the damage, two grids with cell sizes of $50 \mathrm{~m}$ and $100 \mathrm{~m}$ were created using Create Fishnet (ArcGIS 10.5, ESRI, Redlands, CA, USA). The damaged area in each cell was calculated by using Zonal statistics (ArcGIS 10.5, ESRI, Redlands, CA, USA). The ratio between the damaged area and the grid cell area was then calculated for each cell in the two grids and expressed as a percentage. This process generated damage assessment map in which the damaged area is presented per unit area (50 m grid) (Figure 7).

\subsection{Accuracy Assessment}

Validation was derived from optical images from 14 March 2011 using Google Earth (high spatial resolution imagery). Overall accuracy, user's (UA) and producer's (PA) accuracies and Kappa coefficient were used to define the accuracy. Independent samples were randomly tested versus the imagery results (over 400 random distributed points). This was applied for both the entire scene and specific smaller sections were tested, such as inland and along the coastline (Figure 5).

\section{Results and Discussion}

To detect and identify the level of change in the study area, the results were presented according to the protocol outlined in Figure 2. The interferometric coherence maps of both periods, i.e., pre-event pair (left image) and co-event pair (right image), are presented in Figure 3. Light tones (high coherence 
values) indicate areas with slight or no change, while dark tones (low coherence values) mark areas that have undergone change. A simple visual examination shows that the most noticeable differences in both maps are evident between the coastline and inland areas. Along the coastline, changes are easily observed before and after the event, but the co-event map shows that most of the coastline area has changed. In contrast to the coastline, the inland areas show high stability, with no changes or slight changes in both maps.

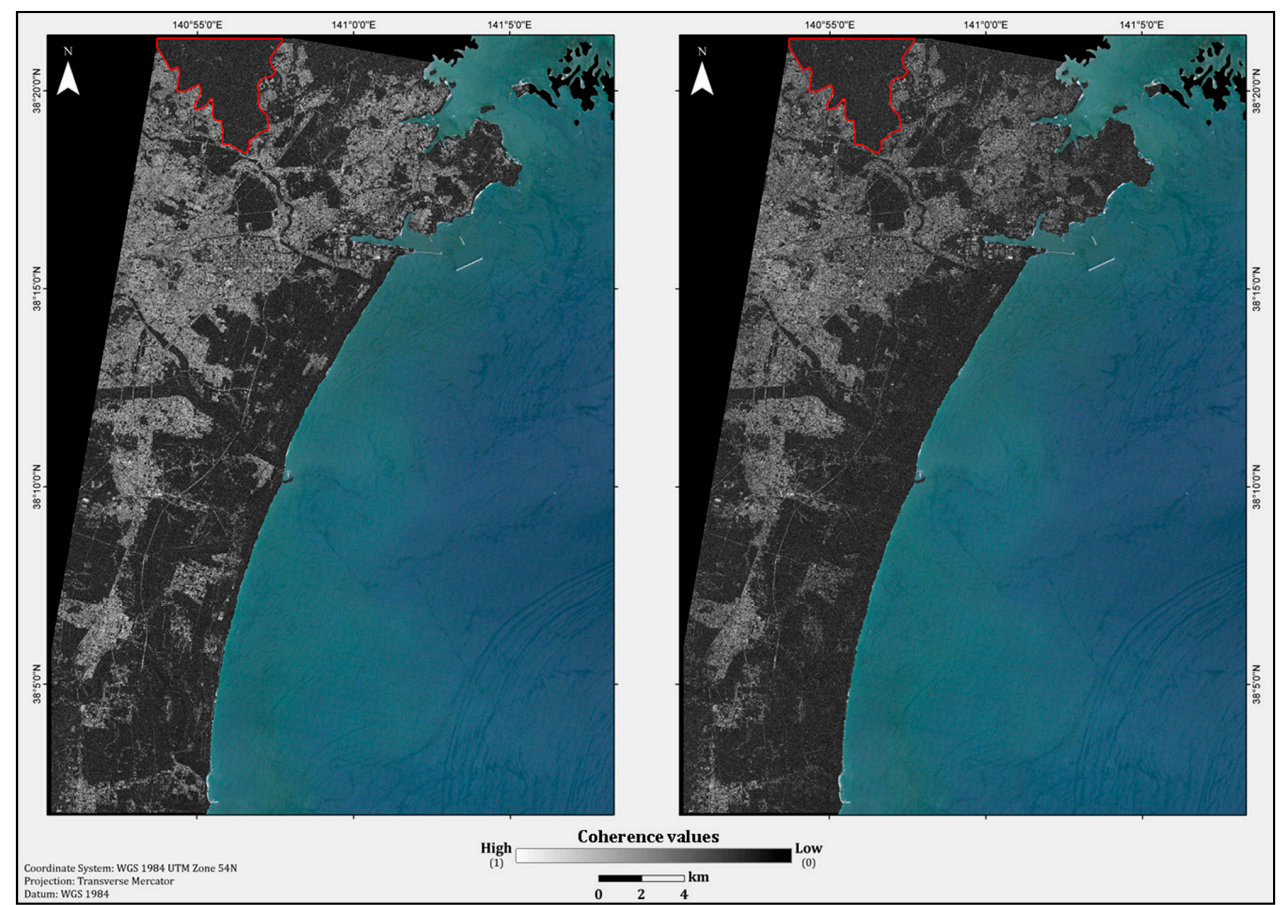

(a)

(b)

Figure 3. InSAR coherence maps overlying the Landsat 5 image: (a) pre-event coherence map; and (b) co-event coherence map. Light tones (high coherence values) represent no change. Dark tones represent changes (low coherence values). Red polygon represents low coherence values due to vegetation cover, see text for further explanation.

In general, a clear distinction exists in the level of change evident along the coastline, which experienced the most significant damage and its coherence values are correspondingly low, compared to that in the inland area. In contrast to the coastline, inland areas suffered much less damage overall, which is reflected in their generally high coherence values, but certain inland areas exhibited unusually low coherence. For example, the region located to the northwest of the study area (Figure 3, area outlined in red) displays low coherence values both pre- and co-event. Situated too far inland, this area was not affected by the tsunami.

In regions that have experienced major natural disasters, data collected during the period prior to the event contributes valuable information toward understanding the pre-event nature of the land cover. The inland regions of interest that display low coherence are suspected to have exceptionally high vegetation cover, the presence of which markedly influences the results, causing an apparent loss of coherence [27-29]. Observations of the X-band are the most strongly affected [30], as that wavelength penetrates the upper part of the vegetation cover, such as the canopy and branches [30], and causes volumetric scattering. Furthermore, even slight, wind-generated movement of vegetation causes a loss of coherence, as shown previously by [27].

To determine with certainty that the low coherence values were the result of changes due to the tsunami event and not due to changes in vegetation cover caused either by winds or phenology, a vegetation mask was applied using the NDVI values extracted from the Landsat image. The obtained 
pre-event NDVI map is presented in Figure 4, where light tones signify vegetated areas, and dark tones signify non-vegetated areas, such as urban areas or man-made structures.

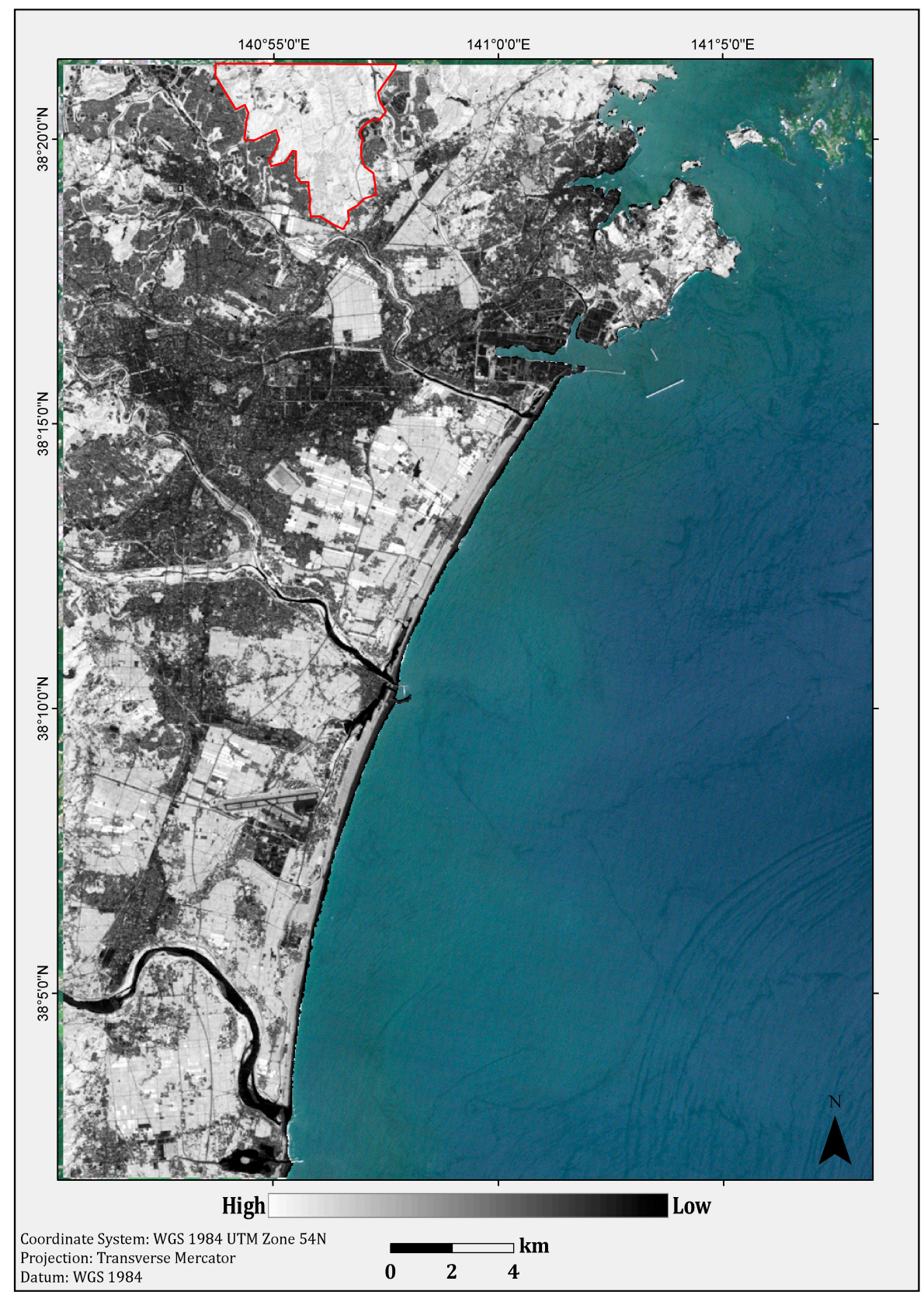

Figure 4. NDVI map. Light shades represent vegetated areas, observed mostly along the coastline. Dark shades represent urban areas or man-made structures, and they mostly appear in the inland areas. The red polygon represents a suspected area that was found to be a vegetated area.

Once the results for both the coherence and NDVI were obtained, thresholds were applied accordingly, and the two layers were then used to mask the co-event coherence results. A schematic of the procedure and the resulting combined map obtained after masking for the two thresholds are shown in Figure 5. By eliminating the extracted vegetation data, the combined map enables damaged buildings to be distinguished from undamaged structures in the wake of the earthquake and tsunami events. The combined map (Figure 5) could, therefore, be divided into three major classes: (1) vegetation; (2) damaged buildings; and (3) undamaged buildings. 


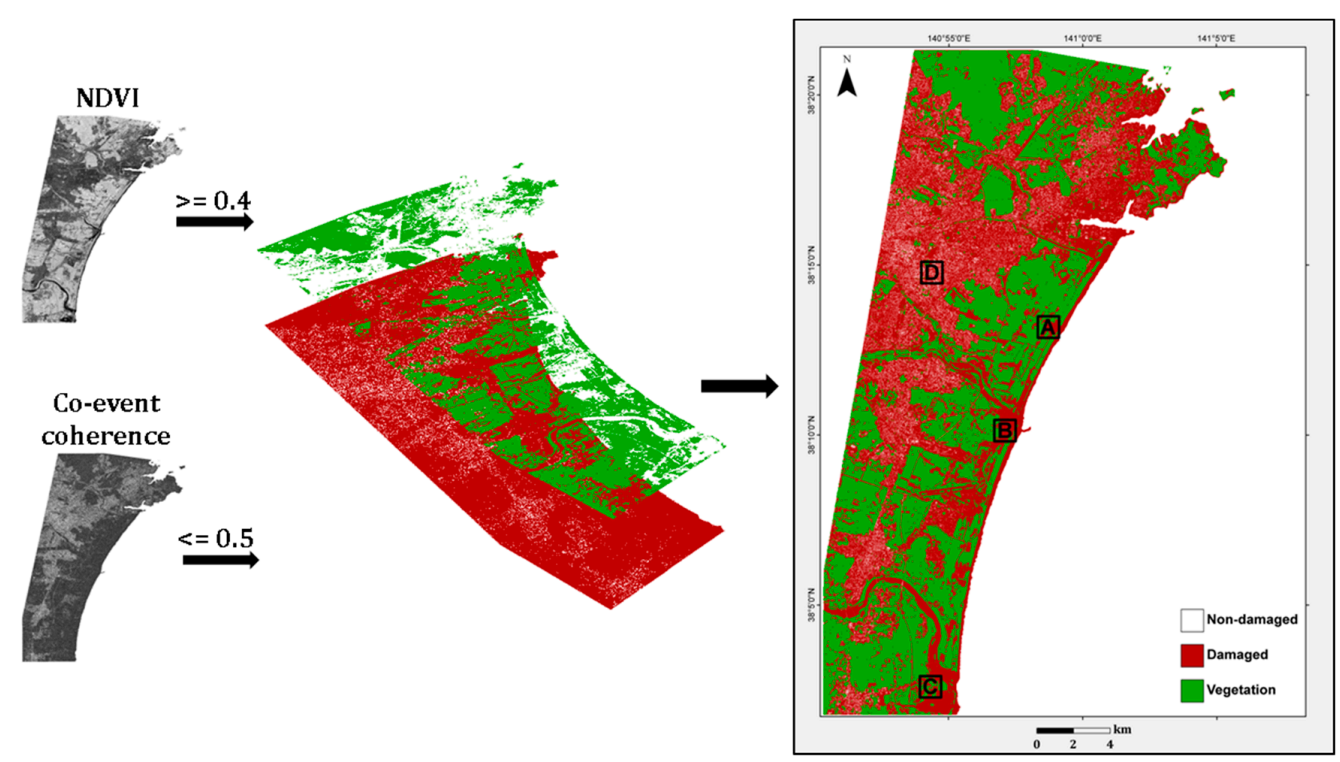

Figure 5. NDVI and co-event coherence maps generated with a threshold of 0.4 and 0.5 , respectively. The combined map displays three classes: vegetated areas (green), damaged (dark red), and undamaged (white) areas. Insets A, B, C, and D are enlarged in Figure 6.

The extent of the observed damage depicted in the combined map was further validated by optical images from 14 March 2011 using Google Earth (Figure 6). Note that on that date (the same day as the post-event SAR acquisition), most of the study area was covered by clouds, a condition that supports the use of SAR imagery rather than optical images for damage assessment. Validation of the combined map was tested on sections of the coastline (Figure 6), where the severe damage that occurred due especially to the tsunami wave is clearly evident. This coastal area was characterized by extensive vegetation cover, mostly agricultural fields, which are clearly visible in the pre-event images (Figure 6). After the event, most of these regions were flooded. Despite the severe damage that occurred in these regions, because they were recognized as vegetated land cover in the NDVI map, they were extracted from the final analysis. The results for the built area, the most damaged of which are depicted in red, show that only a few structures remained unchanged (white dots), i.e., were slightly damaged or not damaged at all. In contrast to the coastline, the inland areas exhibit progressively less damage and greater numbers of stable structures, which appear white and represent a very small part of the area (Figure 6D).

Based on the combined map and after the removal of vegetation cover, a damage assessment map was generated. This map (Figure 7) addresses only the built area and is presented with a cell grid size of $50 \mathrm{~m}$. A density map of the damage indicates the zones that were most strongly affected by the 2011 Tohoku earthquake and tsunami event. A damage density of $100 \%$ indicates total destruction. Dark colors represent a high probability of damage, light colors represent a lower probability of damage, and green represents vegetated areas empty of structures, and, as such, these areas were removed from the analysis and are displayed in this map for the sake of clarity. As was previously mentioned, the most severe damage was observed along the coastline, and, accordingly, the colors of the grid cells in that area indicate high damage density (dark colors). As the tsunami wave washed away most of the structures along the coastline, very few structures there were left standing [25]. The lower density of damage observed in more inland areas indicates that the buildings there suffered much less damage. According to [25], the relatively low level of damage observed inland was caused mainly by the earlier seismic events that preceded the Tohoku earthquake. Considering both the inland and coastal regions, damage density values in the range of $1 \%$ to $40 \%$, indicating undamaged or slightly damaged structures, are scarcely observed. This outcome is due primarily to the high sensitivity of the coherence method to changes, especially to subtle changes on the scale of millimeters to centimeters [9]. 
Results accuracies (producer's and user's accuracy and Kappa coefficient) are summarized in Table 2. High overall accuracy (89\%) and a high Kappa coefficient (82\%) were achieved for the entire research area, as for the four enlarged areas in Figure 9 (insets A, B, C, and D). User's and producer's accuracies of the damage class were consistently high, ranging from $76 \%$ to $100 \%$. In specific regions, such as Figure 9B,C, the UA and PA displays values of zero for the no/slight damage class. This is a result of the severe damage observed in the entire scene (Figure 6B,C). Despite the random distribution of the points, most of them were located in damaged areas.
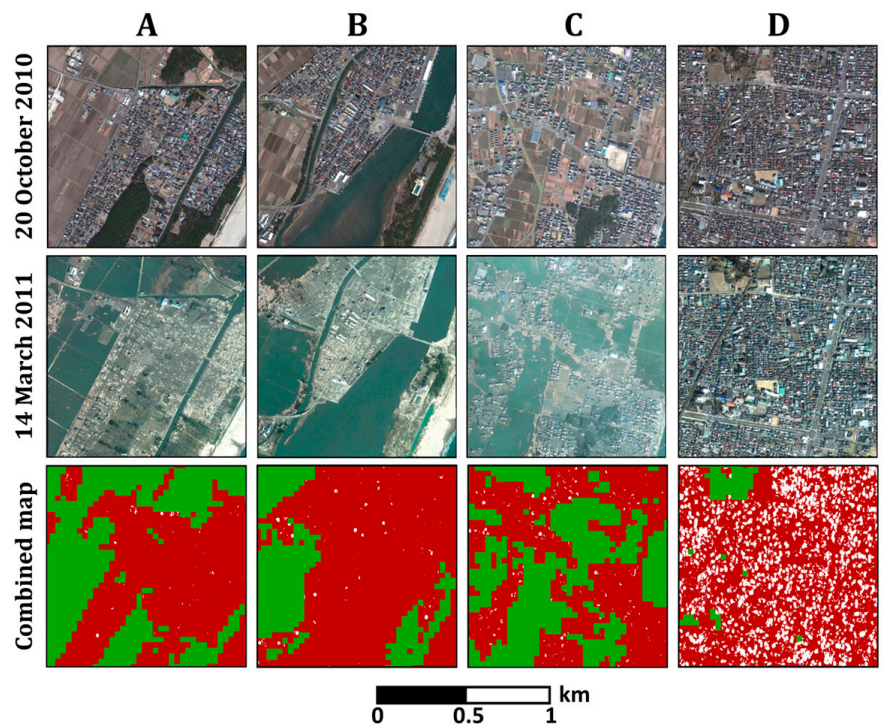

Figure 6. Insets (A-D) showing selected areas from the entire scene (Figure 5). Pre-event optical image; post-event optical image; combined map: vegetation is represented in green, undamaged areas are represented in white, and damaged areas are represented in red.

Table 2. Accuracy assessment (in percentage) for the damage assessment map: overall accuracy, Kappa coefficient, producer's accuracy (PA), and user's accuracy (UA).

\begin{tabular}{ccccccccccccc}
\hline & & \multicolumn{2}{c}{ Entire Scene } & \multicolumn{3}{c}{ A } & \multicolumn{2}{c}{ B } & \multicolumn{2}{c}{ C } & \multicolumn{2}{c}{ D } \\
\hline \multirow{3}{*}{} & & PA & UA & PA & UA & PA & UA & PA & UA & PA & UA \\
\hline \multirow{3}{*}{$50 \mathrm{~m}$} & 89 & 97 & 90 & 100 & 92 & 85 & 96 & 88 & 50 & 100 \\
& Vegetation & 96 & 76 & 100 & 90 & 95 & 97 & 88 & 88 & 100 & 80 \\
& Damage & No/slight damage & 87 & 92 & 50 & 100 & 0 & 0 & 0 & 0 & 95 & 95 \\
& Overall accuracy & 89 & & 94 & & 94 & & 88 & & 92 & \\
& Kappa coefficient & 82 & & 88 & & 84 & & 77 & & 79 & \\
\hline \multirow{2}{*}{$100 \mathrm{~m}$} & Overall accuracy & 82 & & & & & & & & & \\
& Kappa coefficient & 68 & & & & & & & & & \\
\end{tabular}

As urban environments are characterized by very tall, densely-situated buildings with correspondingly high population concentrations, it is of the utmost importance that information about the level of damage be obtained rapidly. This necessitates extracting from the data vital information about the severity of the damage and the most likely locations in built-up areas where rescue missions will be needed in as short a time as possible. However, the choice of grid resolution should be dictated by the desired process run time, as the finer the resolution, e.g., $10 \mathrm{~m}$ or lower, the longer the calculation time. To reduce the calculation time in this study, we tested two grid sizes, $100 \mathrm{~m}$ and $50 \mathrm{~m}$ (Figures 8 and 9). These grid sizes were chosen after examining the average building sizes of several built regions and the dominant terrain in the study area, most of which is relatively flat and lacking any significant changes in topography. For the $50 \mathrm{~m}$ grid size, each cell of the grid contained a small number of 
buildings (approximately 1-8 buildings) together with their surroundings, such as the streets (Figure 8). The $50 \mathrm{~m}$ grid size density map provides detailed information about the damaged area, showing the variance of damage severity and its distribution in the field. In contrast, the $100 \mathrm{~m}$ grid lacks this level of detail about the damage and, instead, shows the area as having undergone more homogenous change, with little variance in damage severity. This cell size was tested because there are buildings in the research area that exceed $100 \mathrm{~m}$ (Figure 8). The results of the test of grid size show that because it differentiates between the levels of damage and spatially represents the area more accurately, the $50 \mathrm{~m}$ grid size is optimal. Furthermore, the overall accuracy and Kappa coefficient were found to be lower for the $100 \mathrm{~m}$ grid, further supporting our decision to use a $50 \mathrm{~m}$ grid (Table 2). For more inland, mountainous regions, however, a smaller cell size should be used, to better account for the influence of changes in topography.

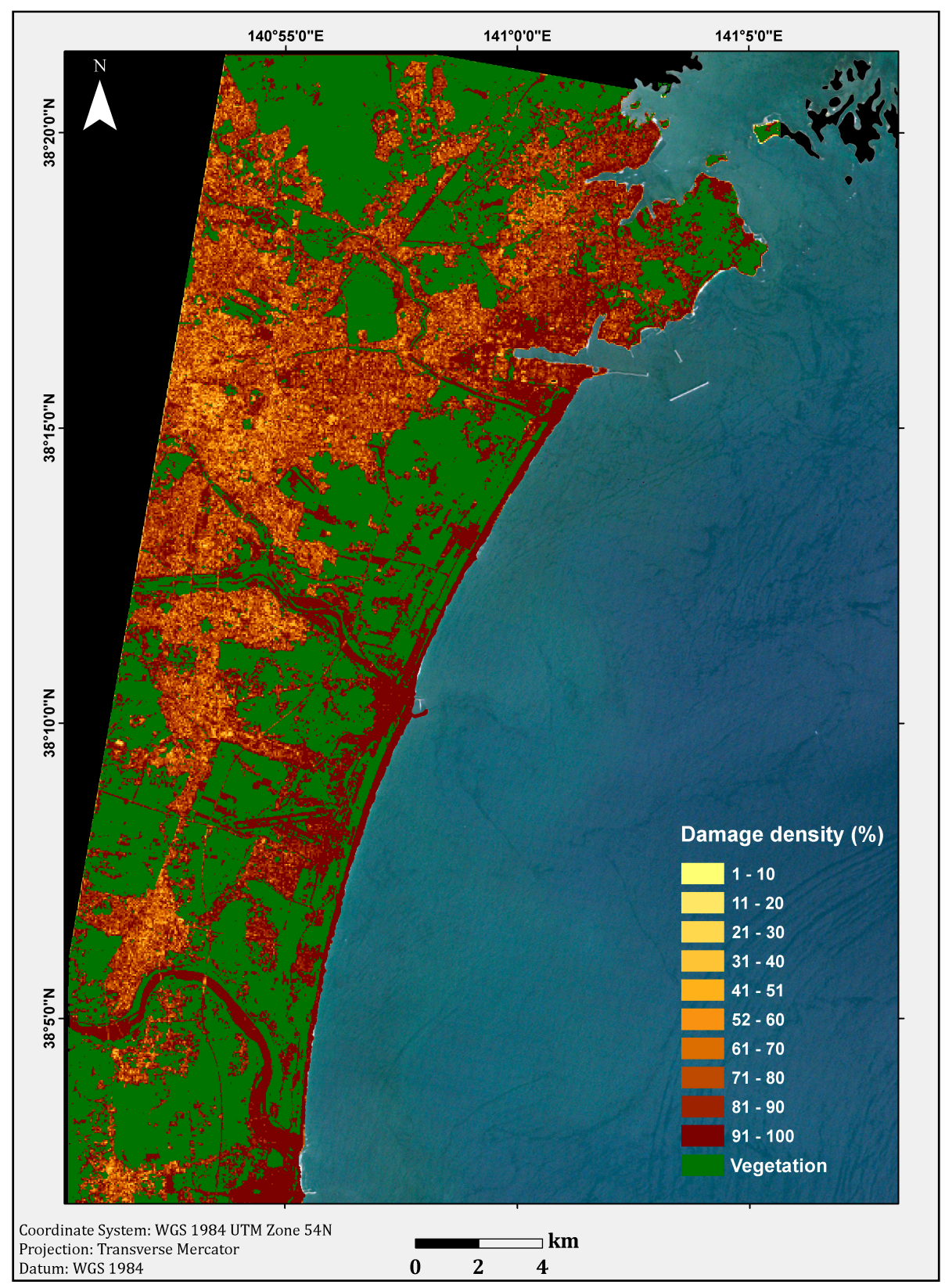

Figure 7. Damage density map per unit area of $50 \mathrm{~m}$. Light colors represent lower probability of damage, dark colors represent higher probability of damage. Green represents vegetation. 


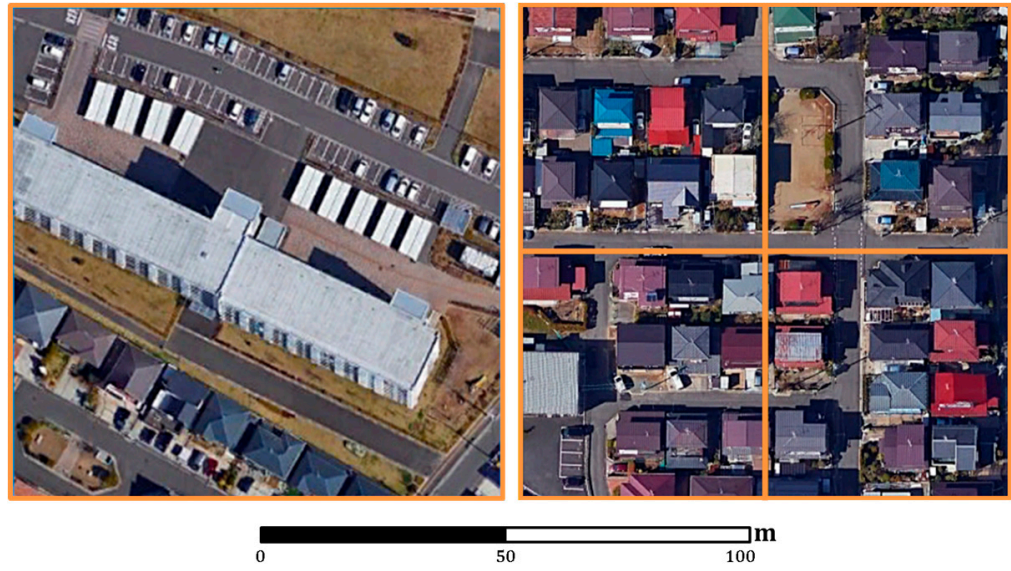

Figure 8. Grid size of $100 \mathrm{~m}$ vs. $50 \mathrm{~m}$, overlying an optical image.

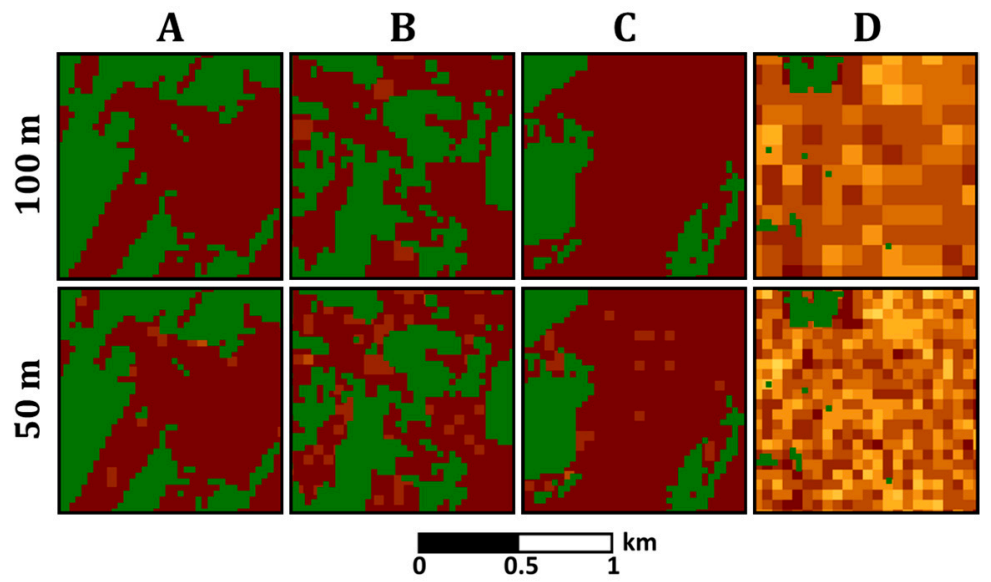

Figure 9. Damage density maps with grid size of $100 \mathrm{~m}$ vs. $50 \mathrm{~m}$. Insets (A-D) showing selected areas from the entire scene, display the differences of the damage distribution between the two grids.

In this study, the damage level was divided into 10 classes to ensure that it was depicted in sufficient detail to obtain valuable information. Previous studies classified the building damage into several basic grades (usually three or four classes) at the block level $[3,11,23]$. Since the proposed approach in this study quantitatively evaluated the extent of change to the landscape, it enables the damage level to be divided into a greater number of classes to obtain finer detail. Thus, the detected damage levels range from no-damage to total destruction, with an additional eight levels of damage between these two extremes (Figure 7). The high level of detail of this approach facilitates the coordination of the rescue teams' capabilities in the field. Moreover, due to the capabilities of TerraSAR-X, especially its high spatial resolution, its cell grid sizes can be easily expanded or reduced without using any ancillary data (such as city blocks).

\section{Conclusions}

This study presented a novel method for mapping the urban damage in the wake of a natural disaster by combining SAR and optical data. To illustrate the methodology, we used a pair of TerraSAR-X images and a Landsat- 5 image to analyze the urban damage that occurred from the 2011 Tohoku earthquake and tsunami in Japan. Due to the high spatial resolution of TerraSAR-X, damage assessment mapping could be applied by using only one coherence map comprising pre- and post-event images. Integration of the co-event coherence map with the NDVI improved the accuracy of the damage assessment by eliminating areas that were falsely identified as damaged and focusing 
only on the urban environment. The $50 \mathrm{~m}$ grid size damage assessment map was better than either the $100 \mathrm{~m}$ grid size or the smaller size grid in terms of the level of accurate detail it provided (high overall accuracy and Kappa coefficient, 89\% and 82\% respectively) about the locations and states of damaged buildings and structures, valuable information that could be exploited to aid rescue missions.

The remote sensing method tested in this research is particularly useful for the immediate response after a natural or man-made disaster event, as it can be implemented easily to rapidly identify and assess the damage to buildings and other man-made structures in urban environments. Moreover, it requires fewer resources, such as time and cost, and it provides real-time information that is that can be easily interpreted to gain a clear understanding of the damage.

Author Contributions: All authors contributed equally to the development of this research.

Acknowledgments: The authors wish to thank the Ministry of Science, Technology, and Space of Israel and the Italian Space Agency (ASI) for their partial support of this study. In addition, the authors thank German Aerospace Centre (DLR) for TerraSAR-X data, which was provided free of charge in the framework of the funded research proposal ID: GEO0053.

Conflicts of Interest: The authors declare no conflict of interest.

\section{References}

1. Oštir, K.; Veljanovski, T.; Podobnikar, T.; Stančič, Z. Application of satellite remote sensing in natural hazard management: The Mount Mangart landslide case study. Int. J. Remote Sens. 2003, 24, 3983-4002. [CrossRef]

2. Plank, S. Rapid damage assessment by means of multi-temporal SAR-A comprehensive review and outlook to Sentinel-1. Remote Sens. 2014, 6, 4870-4906. [CrossRef]

3. Uprety, P.; Yamazaki, F. Use of high-resolution SAR intensity images for damage detection from the 2010 Haiti earthquake. In Proceedings of the 2012 IEEE International Geoscience and Remote Sensing Symposium (IGARSS), Munich, Germany, 22-27 July 2012; pp. 6829-6832.

4. Joyce, K.E.; Belliss, S.E.; Samsonov, S.V.; McNeill, S.J.; Glassey, P.J. A review of the status of satellite remote sensing and image processing techniques for mapping natural hazards and disasters. Prog. Phys. Geogr. 2009, 33, 183-207. [CrossRef]

5. Dong, L.; Shan, J. A comprehensive review of earthquake-induced building damage detection with remote sensing techniques. ISPRS J. Photogramm. Remote Sens. 2013, 84, 85-99. [CrossRef]

6. Yamazaki, F.; Kouchi, K.; Kohiyama, M.; Muraoka, N.; Matsuoka, M. Earthquake damage detection using high-resolution satellite images. In Proceedings of the 2004 IEEE International Geoscience and Remote Sensing Symposium, IGARSS'04, Anchorage, AK, USA, 20-24 September 2004; pp. 2280-2283.

7. Saito, K.; Spence, R.J.; Going, C.; Markus, M. Using high-resolution satellite images for post-earthquake building damage assessment: A study following the 26 January 2001 Gujarat earthquake. Earthq. Spectra 2004, 20, 145-169. [CrossRef]

8. Saito, K.; Spence, R.; de C Foley, T.A. Visual damage assessment using high-resolution satellite images following the 2003 Bam, Iran, earthquake. Earthq. Spectra 2005, 21, 309-318. [CrossRef]

9. Ferretti, A.; Monti-Guarnieri, A.; Prati, C.; Rocca, F.; Massonet, D. InSAR Principles-Guidelines for SAR Interferometry Processing and Interpretation; ESA Publications: Noordwijk, The Netherlands, 2007.

10. Chini, M. Earthquake damage mapping techniques using SAR and optical remote sensing satellite data. In Advances in Geoscience and Remote Sensing; InTech: London, UK, 2009.

11. Hoffmann, J. Mapping damage during the Bam (Iran) earthquake using interferometric coherence. Int. J. Remote Sens. 2007, 28, 1199-1216. [CrossRef]

12. Fielding, E.J.; Talebian, M.; Rosen, P.A.; Nazari, H.; Jackson, J.A.; Ghorashi, M.; Walker, R. Surface ruptures and building damage of the 2003 Bam, Iran, earthquake mapped by satellite synthetic aperture radar interferometric correlation. J. Geophy. Res. Solid Earth 2005, 110. [CrossRef]

13. Yamazaki, F. Applications of remote sensing and GIS for damage assessment. In Proceedings of the 8th International Conference on Structural Safety and Reliability, Newport Beach, CA, USA, 17-22 June 2001; pp. 1-12. 
14. Watanabe, M.; Thapa, R.B.; Ohsumi, T.; Fujiwara, H.; Yonezawa, C.; Tomii, N.; Suzuki, S. Detection of damaged urban areas using interferometric SAR coherence change with PALSAR-2. Earth Planets Space 2016, 68,131 . [CrossRef]

15. Milisavljevic, N.; Closson, D.; Holecz, F.; Collivignarelli, F.; Pasquali, P. An approach for detecting changes related to natural disasters using Synthetic Aperture Radar data. Int. Arch. Photogramm. Remote Sens. Spat. Inform. Sci. 2015, 40, 819-826. [CrossRef]

16. Romaniello, V.; Piscini, A.; Bignami, C.; Anniballe, R.; Stramondo, S. Earthquake damage mapping by using remotely sensed data: The Haiti case study. J. Appl. Remote Sens. 2017, 11, 016042. [CrossRef]

17. Matsuoka, M.; Yamazaki, F. Use of satellite SAR intensity imagery for detecting building areas damaged due to earthquakes. Earthq. Spectra 2004, 20, 975-994. [CrossRef]

18. Yonezawa, C.; Takeuchi, S. Decorrelation of SAR data by urban damages caused by the 1995 Hyogoken-nanbu earthquake. Int. J. Remote Sens. 2001, 22, 1585-1600. [CrossRef]

19. Arciniegas, G.A.; Bijker, W.; Kerle, N.; Tolpekin, V.A. Coherence-and amplitude-based analysis of seismogenic damage in Bam, Iran, using Envisat ASAR data. IEEE Trans. Geosci. Remote Sens. 2007, 45, 1571-1581. [CrossRef]

20. Liao, M.; Jiang, L.; Lin, H.; Huang, B.; Gong, J. Urban change detection based on coherence and intensity characteristics of SAR imagery. Photogramm. Eng. Remote Sens. 2008, 74, 999-1006. [CrossRef]

21. Dell'Acqua, F.; Gamba, P. Remote sensing and earthquake damage assessment: Experiences, limits, and perspectives. Proc. IEEE 2012, 100, 2876-2890. [CrossRef]

22. Preiss, M.; Stacy, N.J. Coherent change detection: Theoretical description and experimental results. J. Am. Dent. Assoc. 2006, 38, 365-372.

23. Tamkuan, N.; Nagai, M. Fusion of multi-temporal interferometric coherence and optical image data for the 2016 kumamoto earthquake damage assessment. ISPRS Int. J. Geo-Inf. 2017, 6, 188. [CrossRef]

24. Mori, N.; Takahashi, T.; Yasuda, T.; Yanagisawa, H. Survey of 2011 Tohoku earthquake tsunami inundation and run-up. Geophys. Res. Lett. 2011, 38. [CrossRef]

25. Kazama, M.; Noda, T. Damage statistics (Summary of the 2011 off the Pacific Coast of Tohoku Earthquake damage). Soils Found. 2012, 52, 780-792. [CrossRef]

26. Hanssen, F.R. RADAR Interferometry: Data Interpretation and Error Analysis, 1st ed.; Springer: Dordrecht, The Netherlands, 2002.

27. Havivi, S.; Amir, D.; Schvartzman, I.; August, Y.; Maman, S.; Rotman, S.R.; Blumberg, D.G. Mapping dune dynamics by InSAR coherence. Earth Surf. Process Landf. 2017, 43, 1229-1240. [CrossRef]

28. Zebker, H.A.; Villasenor, J. Decorrelation in interferometric radar echoes. IEEE Trans. Geosci. Remote Sens. 1992, 30, 950-959. [CrossRef]

29. Rosen, P.A.; Hensley, S.; Joughin, I.R.; Li, F.K.; Madsen, S.N.; Rodriguez, E.; Goldstein, R.M. Synthetic aperture radar interferometry. Proc. IEEE 2000, 88, 333-382. [CrossRef]

30. Hong, S.; Wdowinski, S.; Kim, S. Evaluation of TerraSAR-X observations for wetland InSAR application. IEEE Trans. Geosci. Remote Sens. 2010, 48, 864-873. [CrossRef]

(C) 2018 by the authors. Licensee MDPI, Basel, Switzerland. This article is an open access article distributed under the terms and conditions of the Creative Commons Attribution (CC BY) license (http://creativecommons.org/licenses/by/4.0/). 